\title{
UPAYA PENGELOLA PKBM DALAM MENINGKATKAN LITERASI BUDAYA BACA MELALUI TAMAN BACAAN MASYARAKAT
}

\author{
Lilis Karwati \\ Pendidikan Masyarakat, FKIP, Universitas Siliwangi \\ liliskarwati@unsil.ac.id
}

\begin{abstract}
Abstrak
Membaca dapat meningkatkan pengetahuan yang belum pernah diketahui sebelumnya, akan tetapi kurangnya minat baca masyarakat disebabkan oleh kesibukan dalam kegiatan seharian dengan berbagai macam aktifitas yang dilakukan masyarakat, bahkan kebanyakan masyarakat lebih senang menggunakan gawai dari pada harus membaca buku. Maka pengelola PKBM berinisiatif mengajak masyarakat khususnya warga belajar untuk memanfaatkan waktu luangnya melalui kegiatan budaya baca di perpustakaan sebagai Taman Bacaan masyarakat PKBM GEMA Kota Tasikmalaya. upaya yang dilakukan pengelola dalam meningkatkan literasi budaya baca dengan melakukan berbagai perlombaan membaca, pembacaan puisi kreatif, membacakan buku, buku bergambar, cerita dan promosi buku. Tujuannya memanfaatkan waktu luang untuk meningkatkan keilmuan yang dapat bermanfaat bagi masyarakat dalam menambah wawasan pengetahuan sesuai dengan kebutuhan. Metode penelitian yang digunakan yaitu deskriptif kualitatif Teknik observasi, wawancara, serta dokumentasi. Analisis penelitian menunjukan kegiatan budaya baca melalui taman bacaan di PKBM GEMA dapat meningkatkan wawasan pengetahuan ketrampilan masyarakat untuk lebih kreatif dan inovatif, Simpulan upaya yang dilakukan oleh pengelola melalui literasi Budaya Baca dalam pelaksanaannya membantu pembiasaan masyarakat dalam membaca serta memberikan informasi sebagai bekal dalam meningkatkan kecakapan hidup

Kata kunci: Upaya Pengelola, literasi, Budaya Baca.
\end{abstract}

\begin{abstract}
Reading can increase knowledge that has never been known before, but the lack of public interest in reading is caused by being busy in activities all day long with various kinds of activities carried out by the community, even most people prefer to use gadgets instead of having to read books. So the PKBM manager took the initiative to invite the community, especially residents to learn to take advantage of their spare time through reading culture activities in the library as the Community Reading Park of the PKBM GEMA community in Tasikmalaya City. the efforts made by the manager in increasing literacy in the reading culture by holding various reading competitions, creative poetry reading, reading books, picture books, stories and book promotion. The goal is to take advantage of free time to increase knowledge that can be useful for the community in increasing knowledge knowledge according to their needs. The research method used is descriptive qualitative observation, interview, and documentation techniques. The research analysis shows that reading culture activities through the reading garden at PKBM GEMA can increase the knowledge of community skills to be more creative and innovative. Conclusion of the efforts made by managers through reading culture literacy in its implementation helps people habituate reading and provides information as provisions for improving life skills

Keywords: Management Efforts, literacy, Reading Culture.
\end{abstract}

\section{PENDAHULUAN}

Membaca merupakan salah satu cara memperoleh wawasan dalam mengembangkan ilmu pengetahuan bagi seseorang, dengan membaca kita dapat mengerti dan memahami halhal yang belum pernah diketahui sebelumnya, melihat perkembangan saat ini membaca 
merupakan suatu hal penting untuk dibiasakan, mengingat membaca merupakan bahasa komunikasi lewat tulisan sudah menjadi kebutuhan yang paling sering digunakan. Dalam buku budaya literasi. UNESCO (2012) menyebutkan minat baca di Indonesia memprihatinkan, hanya $0,001 \%$ atau hanya 1 orang yang rajin membaca dari 1000 orang Indonesia. Menurut riset World's Most Literate Nations 2016, Indonesia dinyatakan menduduki peringkat ke 60 dari 61 negara dalam minat membaca. Ironisnya, meski minat baca buku rendah tapi data We Are Social per Januari 2017 mengungkap orang Indonesia bisa menatap layar gadget kurang lebih 9 jam/hari.sedangkan menurut karya Neng Gustini (2016:4) bahwa masyarakat Indonesia dalam dalam pembiasaan membaca masih rendah masyarakat lebih memilih banyak menonton televisi $(85,9 \%)$ dan mendengarkan radio 2 $(40,3 \%)$ daripada membaca $(23,5 \%)$. Artinya pembiasaan membaca dalam memperoleh informasi baru dilakukan oleh $23,5 \%$ dari total penduduk Indonesia. Dalam upaya mencerdaskan bangsa seseorang dapat meningkatkan wawasan pengetahuan melalui membaca karena dengan membaca akan membuka wawasan seseorang dalam mengembangkan keilmuanya akan tetapi dalam pelaksanaan membaca tak semudah dilakukan minimal harus ada motivasi dengan ketertarikan terhadap minat dan kebutuhan dalam menurut Shaleh (2004:262) Menyatakan bahwa adanya dorongan minat untuk melakukan suatu tindakan dengan adanya ketertarikan untuk melakukan suatu perbuatan atas dasar kesadaran untuk bertindak . Menurut Tn (2017) Menyatakan Minat menurut Crow and Crow yaitu suatu hal yang memiliki hubungan dengan adanya unsur kekuatan yang menjadidaya gerak yang dilakukan seseorang dalam mendukung dan bertindak terhadap kegiatan yang akan di lakukanya. Dalam pelaksanaanya pembiasaan yang dilakukan seseorang dalam kegiatan membaca buku merupakan hal yang tidak semua orang menyukainya, terkadang sebagian orang berpendapat dengan kegitan membaca buku menimbuklkan kejenuhan dan membosankan karena buku yang di baca kurang menarik akan tetapi ada juga sebagian orang membaca buku sudah menjadi pembiasaan dilakukan dalam meningkatkan wawasan keilmuan yang sangat bermanfaat dalam kehidupan.

Banyak penyebab kurangnya motivasi literasi khususnya masyarakat pada zaman sekarang karena kebanyakan mereka lebih memilih kegiatan lain yang tidak terlalu membosankan baginya seperti main game, chat whatsapp web, berbelanja, ngobrol, melihat you tube dan lain-lain, Banyak penyebab kurangnya motivasi literasi khususnya masyarakat lingkungan PKBM. salah satu upaya dalam membantu mencerdaskan bangsa melalui kegiatan membaca yang diselenggarakan dalam meningkatkan budaya baca pada masyarakat umumnya dan pada pesrta didik yang yang mengikuti kegiatan dalam program taman bacaan yang di selenggarakan oleh pengelola PKBM merupakan Program Pendidikan Masyarkat melalui kegiatan pemberdayaan masyarakat melalui pengembangan gerakan literasi budaya baca pada masyarakat dalam upaya meningkatkan wawasan pengetahuan yang lebih baik menuju kehidupan yang berkepribadian dalam pergaulan kehidupan bermasyrakat. Menurut Kamil (2011:16) berpendapat pembelajaran yang diselenggarakan dalam pendidikan non formal mencakup ranah pengetahuan dan keterampilan yang berhubungan terhadap aspek dimana manusia dapat menjalankan kehidupan, sehingga dalam upaya pemenuhan kebutuhan dalam kehidupannya manusia harus belajar sebagai upaya menjalani kehidupan sebagai 
pemecahan permasalahan yang dihadapinya baik secara pribadi maupun bermasyarakat. Sedangkan menurut Henry (2008:7) budaya membaca adalah sebagai upaya yang dilakukan dalam memperoleh pesan yang di sampaikan dalam buku atau media lain dalam bentuk kata atau kalimat yang mengandung makna arti dalam wawasan pengembangan pengetahuan dengan memiliki tujuan tertentu dalam memperoleh informasi yang bermanan baik isi maupun makna bacaan. Sedangkan Sutarno dalam Helzi (2013:143) berpendapat bahwa untuk mengelompokan faktor yang dapat mempengaruhi dalam minat membaca antara lain;

a. Adanya rasa keingin tahuan masyarakat berdasarkan pada fakta, teori, prinsip dan pengetahuan tentang informasi yang diinginkan.

b. Adanya bahan bacaan sebagai bahan media yang menarik berkualitas sesuai dengan kebutuhan masyarakat.

c. Menyediakan waktu luang yang dapat di manfaatkan untuk kegiatan membaca.

d. Adanya keingintahuan masyarakat terhadap informasi yang actual dan baru

e. Memiliki prinsip yang kuat bahwa membaca adalah suatu kebutuhan rohani dalam memperoleh wawasan, pengalaman dan pengetahuan

Dalam upaya meningkatkan budaya minat baca masyarakat di atur dalam undangundang dasar no 43 tahun 2007 tentang perpustakaan sedangkan dalam pasal 7 undangundang perpustakaan pemerintah berkewajiban untuk memberikan dukungan sebagai upaya dalam system pendidikan Nasional dalam menjamin penyelenggaraan dan pengelolaan perpustakaan sebagai pusat sumber belajar masyarakat secara adil dan merata di seluruh tanah air. Sedangkan menurut pasal 48 dan pasal 51 yang mengatur tentang pembudayaan kegemaran membaca yang dapat dilakukan oleh keluarga, satuan pendidikan dan masyarakat yang di fasilitasi oleh pemerintah daerah dalam pengadaan buku-buku yang berkualitas.

\section{KAJIAN TEORI}

Menurut DITJEN PAUD DIKMAS (2015) gerakan literasi keluarga sebagai upaya menindaklanjuti dari program pemberatasan buta aksara dengan mendapat penghargaan dari UNESCO pada tahun 2012 tentang capaian program budaya baca angka melek aksara sebesar 96,51\% (sumber: gln.kemendikbud.go.id). Selanjutnya menurut kementrian pendidikan dan kebudayaan pada tahun 2016 yang menggalakan program literasi Nasional sebagai bagian dari implementasi peraturan menteri pendidikan dan kebudayaan nomor 23 tahun 2015 tentang pertumbuhan budi pekerti, melalui Gerakan Literasi Nasional (GLN), Gerakan Literasi Sekolah G (GLS), Gerakan Literasi Bangsa (GLNB), Gerakan Indonesia Membaca (GIM), Gerakan Nasional Orang Tua Membaca Buku (GERNAS BAKU) Sedangkan Menurut Ibnu Aji Setiawan (2018) berpendapat bahwa literasi merupakan kemampuan dan keterampilan yang dimiliki individu dalam meningkatkan kemampuan dalam katalistung yaitu membaca,menulis, berbicara dan berhitung guna meningkatkan keahlian yang dibutuhkan dalam menjalani kehidupan sebagai upaya pemecahan maslah yang di hadapinya. Rokhman (2018) berpendapat bahwa dalam penguasaan literasi dasar yang telah disepakati oleh World Economic Forum pada tahun 2015 orang tua dan seluruh warga masyarakat menjadi bagian penting dalam kegiatan literasi di antaranya literasi baca tulis, literasi sains, literasi digital, literasi finansial dan literasi budaya dan kewarganegaraan. 
Lembaga masyarakat yaitu pusat kegiatan belajar masyarakat yang mengelola program kegiatan Taman Bacaan Masyarakat telah yang berupaya memberikan pelayanan yang terbaik bagi masyarakat yang dibuat dari, oleh dan untuk masyarakat, PKBM dalam kegiatannya membantu memfasilitasi masyarakat untuk belajar melalui pemanfaatan waktu luang melalui budaya baca sehingga menjadi pembiasaan masyarakat dalam belajar guna menambah pengetahuan serta dapat mengikuti juga mengikuti program lain yang di selenggarakan PKBM guna kebutuhan masyarakat dan memiliki kesempatan dapat melanjutkan pada jenjang pendidikan yang lebih tinggi. Menurut Pramuji Wibowo (2013) juga mengatakan, fungsi utama PKBM adalah menyediakan:

a. pendidikan dan pelatihan

b. sebagai pelayanan Informasi dan Sumber Belajar bagi Masyarakat

c. tempat Aktifitas dalam Pengembangan Masyarakat

d. tempat berkoordinasi dalam mengembangakan jaringan social dalam masyarakat

Pengelola PKBM GEMA berinisiatif mengajak masyarakat dan peserta didik untuk menyempatkan membaca melalui pemanfaatan waktu luang dan pentingnya menambah wawasan penetahuan .pengelola selalu berupaya menyediakan buku buku yang berkualitas yang dapat dibaca oleh masyarakat sebagai upaya mengembangkan budaya literasi dalam mendukung gerakan membaca yang menginduk pada gerakan literasi Nasional, penulis ingin mengangkat judul Upaya Pengelola PKBM Dalam Meningkatkan Literasi Budaya Baca Melalui Taman Bacaan Masyarakat yang dapat di rumuskan dalam rumusan masaslah yaitu: Bagaimana upaya pengelola PKBM dalam Dalam Meningkatkan Literasi Budaya Baca Melalui Taman Bacaan Masyarakat melalui program Budaya Baca dengan Manfaat taman bacaan PKBM yang telah di sediakan, yang dapat menjadikan pembiasaan dalam membudayakan kegiatan membaca di lingkungan PKBM keluarga dan di masyarakat. Pihak penegelola PAUD di PKBM GEMA, dapat mengembangkan melaksanakan kegiatan budaya Gerakan literasi senantiasa terus bersama pemerintah dan Pendidikan masyarakat. Dari beberapa pengertian diatas kegiatan budaya baca memiliki tujuan masyarakat /peserta didik memiliki pembiasaan membaca dalam memanfaatkann waktu luang. Dan PKBM GEMA sendiri mampu untuk membudayakan baca buku kepada masyarakat melaui taman bacaan sehingga dapat, meningkatkan minat baca banyak menyangkut teknis namun yang lebih penting dari itu adalah kesatuan antara pembelajaran refleksi dan aplikasinya yang dapat memecahkan masalah yang dihadapi dalam kehidupannya.

\section{METODE PENELITIAN}

Metode penelitian yang digunakan adalah metode deskriptif kualitatif sebagai upaya gambaran yang di gunakan dalam meneliti masalah yang digunakan dalam mencapai tujuan yang diharapkan oleh peneliti menurut Sugiyono (2009:2) mengatakan bahwa "Metode penelitian pada dasarnya merupakan cara ilmiah untuk mendapatkan data dengan tujuan dan kegunaan tertentu. Adapun penelitian penulis ajukan dengan judul upaya pengelola PKBM dalam meningkatkan literasi budaya baca melalui taman bacaan masyarakat. Subjek Penelitian pengelola PKBM GEMA, Tutor PKBM, pengelola kegiatan Budaya Baca, Lokasi Penelitian ini dilakukan PKBM GEMA Kota Tasikmalaya. Teknik pengumpulan data melalui 
wawancara, observasi, dokumentasi, gambaran penelitian apa saja upaya tutor dalam meningkatkan budaya baca masyarakat sehingga masyarakat mau untuk membiasakan membaca guna kepentingan untuk meningkatkan wawasan pengetahuan dalam upaya memecahan masalah yang dihadapinya.

\section{HASIL DAN PEMBAHASAN}

Upaya pengelola pkbm gema dalam meningkatkan minat baca masyarakat di taman bacaan yang di kelola oleh pkbm berbagai upaya untuk mengajak masyarakat khususnya warga belajar bkbm dalam meanfaatkan waktun luang sebelum pembelajarn di mulai atau masyarakat yang ada di sekitar tempat kegiatan intuk memanfaatkan fasilitas yang tersedia dan pengelola selalu berupaya mengajak masyarakat untuk melaukan keguatan literasi, hal ini bukan lah hal yang mudah karena masyarakat lebih tertarik dengan menggunakan aplikasi hp untuk melalukan chat baik melalui aplikasi hp untuk melalukan chat baik melalui aplikasi media sosial daripada harus membaca buku ,maka peneliti menemukan beberapa faktor yang mempengaruhi minat membaca dalam kegiatan budaya baca di PKBM GEMA:

a. Tersedianya bahan bacaan yang menarik untuk di baca sehingga dapat menunjang kegiatan budaya baca

b. Adanya waktu yang tersedia untuk membaca walaupun hanya sebentar

c. Adanya rasa ingin tahu tentang informasi baru, bukunya menarik sesuai dengan selera pembaca

d. Memliki keyakinan membaca adalah suatu kebutuhan guna meningkatkan wawasan, penegetahuan.

Hasil dari temuan dalam meningkatkan budaya baca dapat digabarkan sebagai berikut:

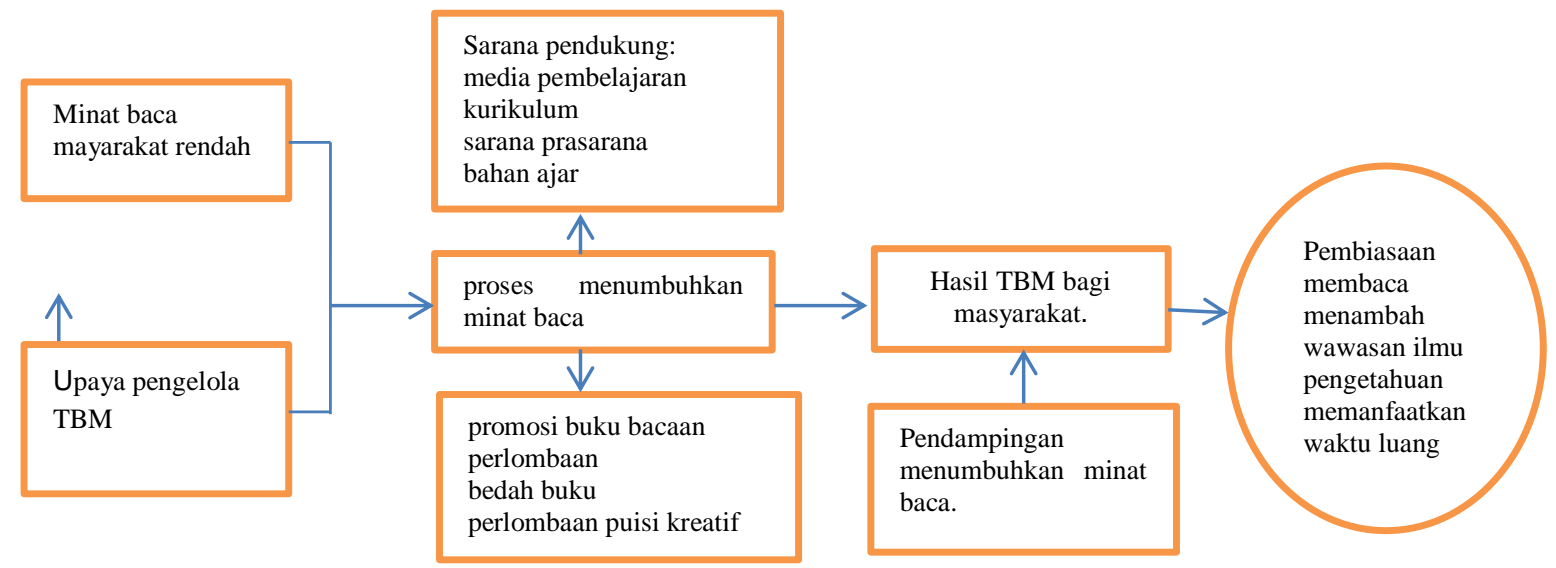

(Sumber: Hasil Pengolahan data)

Berdasarkan data hasil penelitian yang peneliti dapatkan, baik dari data hasil observasi dan wawancara yang dilakukan peneliti sebagai sumber data penelitian serta dari dokumentasi yang peneliti dapatkan, maka peneliti akan melakukan pembahasan mengenai upaya pengelola pkbm dalam meningkatkan literasi budaya baca melalui taman bacaan masyarakat di PKBM GEMA Kota Tasikmalaya. Program Kegiatan Budaya Baca merupakan 
sebuah kegiatan literasi yang diselenggarakan oleh lembaga Pusat Kegiatan Belajar Masyarakat PKBM GEMA bagi masyarakat di lingkungan sekitar dan warga belajar PKBM dalam memanfaatkan waktu luang. Program ini di gagas oleh pengelola PKBM, mengacu pada aturan dan kebijakan kementerian Pendidikan dan Kebudayaan sejak tahun 2016. Melalui program menggalakan Gerakan Literasi Nasional yang diatur dalam peraturan menteri pendidikan dan kebudayaan nomor 23 tahun 2015 tentang penumbuhan budi pekerti yang di implementasikan melalui gerakan literasi seperti Gerakan Literasi Nasional orang tua membacakan buku (GERNAS BAKU).

GERNAS BAKU merupakan upaya melibatkan peran keluarga dalam meningkatkan minat baca anak melalui pembiasaan di rumah, di satuan PAUD dan di Masyarakat, sebelum mengimplementasikan GERNAS BAKU. Tujuan awal dari kegiatan Budaya Baca ini berdasarkan fakta temuan dilapangan adalah untuk mengisi waktu luang pada warga belajar PKBM yang mengikuti program supaya ada kegiatan yang lebih bermanfaat dari pada mengobrol menuggu jam pembelajaran dan bagi masyarakat dalam meningkatkan wawasan membaca melalui pembiasaan membaca. Sejalan dengan tujuan dari Gerakan Nasional Orang tua Membacakan Buku, terdapat 2 tujuan diantaranya membiasakan masyarakat membaca buku yang dilakukan dilinkungan PKBM, menumbuhkan minat baca warga belajar PKBM Gema kota Tasikmalaya. (Berdasarkan hal tersebut kedepannya tentu saja kegiatan Budaya Baca ini bisa saja di integrasikan dengan Gerakan Nasional Orang tua Membacakan Buku.

Upaya-upaya yang dilakukan dalam memanfaatkan waktu luang bagi masyarakat dan warga belajar PKBM GEMA melalui kegiatan budaya baca mencakup beberapa metode antara lain: perlombaan membaca peserta budaya baca dipersilahkan membaca buku yang diminati kemudian diberi kesempatan untuk menelaah buku dan yang paling cepat selesai di beri kesempatan untuk menjelaskan apa yang di bacanya di hadapan temanya, begitu pula dalam perlombaan puisi diberi kesempatan merangkai kalimat puisi yang kemudian dibacakan di hadapan temanya dan peserta terbaik di berikan hadiah . Dalam menumbuhkan minat baca tulis masyarakat dan warga belajar tidak di ajarkan terlebih dahulu akan tetapi mencari inisiatif sendiri membaca puisi yang benar. Selain itu buku buku yang disediakan di perpustakaan PKBM GEMA adalah jenis buku-buku seperti buku dongeng, cerita, pengetahuan dan resep masakan. Buku -buku yang tersedia di dapat dari bantuan pemerintah dan sumbangan warga belajar saat perpisahan dan masyarakat lingkungan setempat. Berdasarkan penelitian yang peneliti lakukan dilapangan buku-buku yang tersedia kebanyakan kebanyakan buku tentang pengetahuan umum, komik. Buku bacaan anak-anak sekolah dan buku tentang pertanian perikanan, buku tentang anak-anak sekolahan, dan buku resep tata boga buku di perpustakaan PKBM pun masih cukup bagus untuk digunakan. sedangkan kegiatan budaya baca di PKBM GEMA pesertanya warga belajar dan masyarakat dalam implementasi pelaksanaaan taman bacaan bersifat non formal akan te tapi tertib secara administrasi.

Dalam pelaksanaan kegiatan promosi buku dilakukan setiap ada buku baru yang masuk ke perputaan taman bacaan PKBM, untuk buku-buku yang di promosikan adalah buku yang memiliki judul yang menarik atau sesuai dengan bahan buku yang di jadikan referensi pembelajaran di PKBM, sehingga warga belajar dan masyarakat memiliki keinginan untuk 
membacanya. Promosi buku baru yang masuk ke perpustakaan selain bantuan pemerintah juga sumbangan warga belajar yang kemudian di sampaikan lewat promosi yang berkaitan dengan isi dari buku tersebut sehingga ada ketertarikan untuk membaca. Hal ini dengan tujuan membelajarkan masyarakat dan warga belajar selain sebagai wawasan pengetahuan yang dimilikinya juga bisa menjadi suatu cerita atau dongeng yang bisa di aflikasikan kepada anaknya dalam keluarga masing masing. Menurut pendapat Hatimah, et al. (2010:177) Upaya untuk membacakan buku, melalui kegiatan yang dilakukan oleh upaya pengelola merupakan suatu cara pengkombinasian melalui tanya jawab dan penugasan yang berujung upaya memotivasi pembaca untuk membaca menulis. Kegiatan budaya baca PKBM GEMA dapat melaksanakan metode kegiatan dalam upaya menumbuhkan minat baca di antaranya perlombaan membacakan buku, pembacaan puisi kreatif, perlombaan buku bergambar, promosi buku, merupakan pelaksanaan yang dilaksanakan oleh pengelola kegiatan budaya baca di PKBM GEMA.

\section{SIMPULAN DAN SARAN}

Berdasarkan uraian dari hasil penelitian dan pembahasan yang telah dilakukan, maka peneliti dapat menarik kesimpulan. Upaya kegiatan literasi Budaya Baca bagi masyarakat dan warga belajar di PKBM GEMA, merupakan salah satu kegiatan untuk membudayakan aktivitas membaca agar masyarakat dapat memanfaatkan fasilitas yang di sediakan oleh pengelola taman bacaan dalam meningkatkan informasi dan memperluas wawasan pengetahuan dalam membiasakan membaca menjadi kegiatan budaya baca. Pengelola kegiatan telah melakukan berbagai cara dalam membantu warga belajar dan masyarakat untuk meningkatkan pembiasaan membaca melalui program literasi budaya baca.

\section{DAFTAR PUSTAKA}

Gustini. (2016). Budaya Literasi (Model Pengembangan Budaya Baca Tulis Berbasis Kecerdasan Mejemuk Melalui Tutor Sebaya). Yogyakarta: Deepublish

Hatimah I, et al. (2010). Pendidikan Keaksaraan Keluarga dan Minat Baca. Bandung: Direktorat Pendidikan Masyarakat, Direktorat Pendidikan Non Formal dan Informal, Kementerian Pendidikan dan Jurusan Pendidikan Luar Sekolah FIP UPI

Henry. (2008). Membaca Sebagai Suatu Keterampilan Berbahasa. Bandung: Angkasa

Kamil, M. (2011). Pendidikan Nonformal Pengembangan Melalui Pusat Kegiatan Belajar Masyarakat (PKBM) di Indonesia (Sebuah Pembelajaran Dari Kominkan di Jepang). Bandung: Alfabeta

Shaleh, (2004). Psikologi Suatu Pengantar dalam Perspektif Islam. Jakarta: Kencana Sugiyono, (2009). Metode Penelitian Kuantitatif Kualitatif dan R\&D. Bandung: Alfabeta Helzi, et al. (2013). "Faktor-Faktor Dominan yang Mempengaruhi Minat Baca Mahasiswa". Jurnal Kajian Informasi dan Perpustakaan 1. (2). 137-145.

Pramuji, W. (2013). Keberlanjutan Kemitraan Pusat Kegiatan Belajar Masyarakat (Jurnal Pendidikan Humaniora). Volume 1 Nomor 1. [Online]. Tersedia: http://journal.um.ac.id/index.php/jph/article/view/3960/759 [19 November 2018]

Setiawan, I.A (2018). Kupas Tuntas Jenis dan Pengertian Literasi. [Online], Tersedia: https://gurudigital.id/jenis-pengertian-literasi-adalah/ [11 November 2018] 
Tn (2017). 10 Pengertian Minat Menurut Para Ahli. [Online], Tersedia: https://dosenpsikologi.com/pengertian-minat-menurut-para-ahli $\quad[11 \quad$ November 2018]

Rokhman (2018). Inilah 6 Literasi Dasar Yang Perlu Anda Tahu . [Online], Tersedia: https://www.kompasiana.com/omank/5a83a394dcad5b29f823ffe2/inilah-6-literasidasar-yang-perlu-anda-katahui?page=all [11 November 2018]

Undang-Undang Republik Indonesia nomor 43 Tahun 2007 Tentang perpustakaan Direktorat Pembinaan Pendidikan Keluarga, Direktorat Jenderal Pendidikan Anak Usia Dini dan Pendidikan Masyarakat Kementrian Pendidikan dan Kebudayaan, 2018.

kebijakan Kementrian Pendidikan dan Kebudayaan tahun 2016 peraturan menteri pendidikan dan kebudayaan nomor 23 tahun 2015 tentang penumbuhan budi pekerti, melalui berbagai gerakan literasi. 